\title{
Movendo a avaliação do português como L2 para além do mal-estar
}

\author{
Ricardo A. de SOUZA 『
}

○

Universidade Federal de Minas Gerais (UFMG)

OPEN ACCESS

\section{COMO CITAR}

Souza, R. A.; Sá, T. M. M.; Amaral,

L. (2020). Movendo a avaliação

do português como L2 para além

do mal-estar. Revista da

Abralin, v. 19, n. 3, p. 763-774,

2020.
Thaís M. M. SÁ $\mathbb{D}$

Centro Federal de Educação Tecnológica de Minas Gerais (CEFET-MG)

Luiz AMARAL

University of Massachusetts Amherst (UMASS Amherst)

\section{Para além do mal-estar na avaliação}

A questão da avaliação da competência e das habilidades de uso de línguas adicionais por seus falantes se impõe nos estudos da linguagem, com um longo histórico de constituição como um objeto de saber especializado e de reflexão sistematizada. De tal saber especializado deriva-se com especial notoriedade a construção de instrumentos padronizados e investidos de reconhecimento oficial para aferição dessas competências e habilidades. São exemplos o CELPE-Bras, para falantes do português brasileiro como L2, assim como o são os testes para a obtenção dos diplomas DELE, os diplomas DELF e DALF, respectivamente para espanhol e o francês como L2, os diplomas da Universidade de Cambridge e os escores do TOEFL e do IELTS, esses três últimos para o inglês como L2.

Por outro lado, a questão da avaliação em línguas adicionais, por razões inquestionavelmente justas, tende a gravitar em torno de debates educacionais. Nessa gravitação, ela se entrelaça com a problemática mais geral trazida pela reflexão em torno da avaliação em sala de aula e o duplo papel dos professores tanto como sustentadores de processos de ensino e aprendizagem quanto como verificadores e juízes do progresso dos estudantes. Em tal reflexão, como demonstra Perrenoud (1999), entre outros, confrontamo-nos com o problema dos usos e abusos das "notas" como instrumentos de regulação e controle, assim como com a desejabilidade da promoção de maior autonomia e autorregulação da própria aprendizagem por parte dos aprendizes. 


\section{REVISTA DA ABRALIN}

Tal como mencionado acima, há uma longa história de estudos a ser narrada sobre a avaliação de competências e habilidades linguísticas. Essa história remonta, no caso anglófono, aos primórdios dos esforços psicométricos, ainda no final do século XIX, como narra brilhantemente Spolsky (1995). Esses esforços resultaram nos estabelecimentos dos testes objetivos, de base estatística, e assim como do campo Psicometria. E tais estabelecimentos, como demonstra o trabalho historiográfico do autor, pavimentaram as estradas que conduziram à criação, nos impérios anglófonos dos dois lados do Atlântico, do TOEFL e dos testes para obtenção dos certificados de proficiência em inglês da Universidade de Cambridge. O primeiro é produto de uma agência de testagem educacional norte-americana (o Educational Testing Service ${ }^{1}$, sediada em Princeton, no estado de New Jersey), os segundos são produtos de um setor da referida universidade, na Inglaterra, que foi denominado University of Cambridge Local Examinations Syndicate até 2005, quando o referido setor passou a receber a denominação mais sintética de Cambridge Assessment ${ }^{2}$.

McNamara (1996) nos traz mais elementos historiográficos sobre os testagem de habilidades em línguas adicionais, sendo que nos chama a atenção em sua narrativa as origens militares do empreendimento para sua criação e, decorrentemente, as prováveis motivações geopolíticas a ele subjacentes. O autor situa a década de 1950 como tendo sido o período inicial da expansão, nos EUA, da produção de testes de habilidades linguísticas em L2. E essa expansão, segundo o autor, se deu em resposta à demanda, por parte do governo norte-americano, de avaliação de pessoal do exército e da CIA, para atuação em territórios fora dos EUA. Será posteriormente, segundo o autor, que a testagem de habilidade em L2 migrará para o contexto do ensino de línguas estrangeiras nas universidades americanas, alinhando-se ao escopo de estudos que informam sobretudo o planejamento curricular do ensino de línguas.

Talvez não seja um salto de imaginação cogitar que ecos das origens motivadas por intenções geopoliticamente suspeitas reverberam em nossas consciências profissionais. Não nos soa tampouco um rompante imaginativo cogitar que tal reverberação se some à lembrança, certamente ainda viva na memória de muitíssimos entre nós, dos impactos para a elitização do acesso à educação superior dos exames vestibulares e da indústria da preparação para eles que proliferou em nosso país. Tal lembrança esbarra na imagem de testes objetivos e de métodos de mensuração e diferenciação de habilidades, colocando-os possivelmente em associações incômodas, e talvez produzindo mal-estar em torno desses objetos de conhecimento.

De fato, não nos parece incomum, em nossas interlocuções com nossos colegas de profissão no Brasil, a prevalência de debates em torno do segundo enquadramento da questão. Ou seja, parece-nos que os debates em torno do tema da avaliação tendem a pender para a problematização dos reais riscos de regulação abusiva das rotas e da negação da singularidade em processos de aprendizagem. O debate parece-nos ganhar fôlego quando o foco é questionamento, necessário e há muito urgentíssimo, das

\footnotetext{
${ }^{1}$ https://www.ets.org/

${ }^{2}$ https://www.cambridgeassessment.org.uk/about-us/who-we-are/our-heritage/
} 


\section{REVISTA DA ABRALIN}

avaliações formais como instrumentos ratificadores das hierarquizações pré-concebidas de corpos, que tornam invisíveis as estruturas sociais que engendram e naturalizam ideologicamente a exclusão.

Um outro fator central muitas vezes negligenciado no desenvolvimento de instrumentos de testagem é a falta de alinhamento entre os construtos embasadores das abordagens de ensino empregadas, as teorias sobre a natureza da linguagem que subjazem as ditas abordagens e os itens usados para testagem desses construtos nos instrumentos de avaliação desenvolvidos. Para além dos testes internacionalmente reconhecidos, como os mencionados acima, a prática cotidiana de professores de línguas adicionais nos mostra exemplos claros da necessidade de uma maior formação técnica na área da avaliação. Ao observarmos tais práticas, é comum encontrarmos exemplos de profissionais que professam o uso de abordagens comunicativas, norteadas por teorias funcionais da linguagem, ao mesmo tempo em que insistem em instrumentos de testagem altamente estruturais, muitas vezes descontextualizados e com um enfoque no conhecimento explícito de formas gramaticais. Esses desencontros entre teorias de aprendizagem, práticas de ensino e mecanismos de testagem levam frequentemente a problemas na relação entre a validade do construto e a validade do conteúdo, como discutido em McNamara (2000).

Porém, insistimos que se soma a esses temas uma outra faceta da questão da avaliação linguística, que não deve jamais ser negligenciada. Trata-se de faceta que pode ser sinteticamente descrita como a investigação dos critérios e dos métodos que assegurem a confiabilidade das informações inferidas através da observação dos desempenhos eliciados por um dado instrumento ou procedimento avaliativo. Note-se que tal faceta é, em última instância, igualmente importante para que as práticas sociais da avaliação sejam justas.

Há situações nas quais, do ponto de vista da exequibilidade administrativa, a aplicação de um teste, prova ou tarefa avaliativa se coloca como a estratégia mais viável para o reconhecimento de habilidades e capacidades desejáveis e, em vários contextos, absolutamente indispensáveis precisamente para que respostas às demandas sociais sejam maximamente éticas. À guisa de exemplo, podemos evocar o questionamento sobre o quão ético e socialmente responsável seria deliberadamente confiar o cargo de professora formadora de novos professores a alguém, sem os indícios de que tal sujeito tivesse as capacitações e, especificamente, as habilidades e competências exigidas para o minimamente adequado exercício da função. Será precisamente na miríade de situações análogas ao exemplo (ainda que menos dramáticas) que se torna absolutamente crítico o grau de confiança que podem depositar nas observações e na extração de informações realizadas através de testes, provas ou tarefas a totalidade dos agentes envolvidos e afetados pela avaliação.

Podemos mover-nos para além do mal-estar na avaliação, ainda, quando tomamos em consideração o interesse científico, transdisciplinar entre os domínios das ciências da linguagem, na validação dos métodos de avaliação de competência e de habilidades linguísticas.

Tal interesse científico transdisciplinar entrelaça a teorização e as práticas de avaliação linguística, por exemplo, com modelos teóricos sobre a representação dos diversos níveis da organização da linguagem. Esse âmbito é exemplificado, tal como o aponta McNamara (2004), na inseparabilidade de testes de conhecimento lexical com modelos sobre o armazenamento de unidades lexicais em 


\section{REVISTA DA ABRALIN}

memória e sobre os mecanismos de acesso mnemônico a essas unidades. Assim, a delimitação de construtos que hipoteticamente constituem as representações linguísticas na mente dos falantes, sua operacionalização em tarefas capazes de eliciar amostras da habilidades deriváveis de tais construtos e, por fim, a validação e a asserção de confiabilidades de instrumentos e métodos que implementam tais tarefas guarda um potencial exploratório e confirmatório dos próprios modelos sobre as arquiteturas de representação e de acesso à linguagem.

O interesse científico nos métodos de avaliação linguística entrelaça-se também aos estudos sobre a aquisição de línguas. Qualquer hipótese teoricamente proposta sobre os fatores que afetam e os mecanismos em operação nas alterações de estados de conhecimentos ao longo do tempo, que possam ser descritas como a aquisição/aprendizagem de competências ou habilidades, pressupõe para o exame de sua plausibilidade empírica a observação criteriosa de tais alterações. Entendemos que deveria ser uma consideração autoevidente e lógica que na ausência de dados robustos que demonstrem a ocorrência de mudanças de estados de conhecimento linguístico, qualquer tomada de posição acerca de fatores e mecanismos aludidos como causais, propulsores ou mediadores da aquisição de línguas fica reduzida a no máximo especulação. Tais dados, por sua vez, em muito dependem tanto para sua coleta quanto para a especificação de sua natureza da existência de instrumentos válidos de avaliação do comportamento linguístico dos falantes.

A compreensão dos critérios e parâmetros de validade e de confiabilidade de avaliações entrelaça-se também com as políticas de educação linguística, seja em níveis institucionais ou macrossociais. Posicionamentos acerca dos resultados alcançados em escala grupal e populacional por programas educacionais deveriam pautar-se pela compreensão razoavelmente profunda dos instrumentos usados para aferir-se tais resultados (ex.: Quais são exatamente os construtos operacionalizados? Quais as características prevalentes nas populações com as quais se comparam amostras? Existem variáveis correlacionadas aos construtos especificados, mas não da mesma natureza, às quais o instrumento é sensível?). No Brasil dos últimos anos testemunhamos o debate em torno da educação de qualidade e como direito dos cidadãos, perpassando questões tão específicas quanto abordagens e métodos de ensino, ser por vezes sequestrado integralmente por retóricas ideológicas e ostensivamente manipulatórias. É nosso entendimento que qualquer discussão sobre a eficácia relativa de programas de educação linguística deve ser orientada pela avaliação de tais programas, o que por sua vez inequivocamente depende da validade de instrumentos de avaliação individual de competências e habilidades.

Há nos estudos da linguagem brasileiros pesquisas em avaliação de competência e habilidades em L2 que enfocam a validação de escalas e testes padronizados e que abordam os impactos dessas escalas e testes para os processos educacionais e a formação docente. Um exemplo é o trabalho de Consolo e Teixeira da Silva (2014), sobre a proposta de um Exame de Proficiência para Professores de Línguas Estrangeiras (EPPLE) adequado ao contexto das licenciaturas em Letras do país. Outro exemplo relevante é o trabalho Scaramucci (2012), acerca do Exame para Certificado de Proficiência em Língua Portuguesa para Estrangeiros (CELPE-Bras). 


\section{REVISTA DA ABRALIN}

O CELPE-Bras, especificamente, é uma bateria que conta com chancela oficial do INEPE (Instituto Nacional de Estudos e Pesquisa Educacionais Anísio Teixeira) e, portanto, também do Ministério da Educação brasileiro. Trata-se de um instrumento desenvolvido com inequívoco critério, e do qual participaram e participam profissionais de reconhecida competência e importância para os estudos linguísticos brasileiros. Há um corpo de conhecimentos erigido em torno deste exame, o que pode ser verificado inclusive através dos documentos públicos disponibilizados no sítio do INEPE que informa acerca do exame ${ }^{3}$.

Há que se considerar, contudo, que o CELPE-Bras é uma bateria de testes, e não um único teste, à semelhança de seus análogos para outras línguas adicionais enumerados no parágrafo que abre a presente seção. As baterias possibilitam grande confiabilidade do resultados observados, entre outros fatores pela possibilidade de confirmação estatisticamente embasada dos fatores que condicionam a variabilidade dos escores nos subtestes, através da verificação de correlações entre os construtos operacionalizados, o que pode dar suporte a afirmações sobre a validade de tais operacionalizações.

O senão em relação às baterias para a avaliação da competência e de habilidades em línguas adicionais, entretanto, é a grande complexidade para sua administração, que usualmente envolve procedimentos que se prolongam por horas, em mais de uma sessão e não raramente exigindo a participação de equipes. Essa questão, somada à possibilidade de restrições e limites ao uso de baterias fora de contextos institucionais muito específicos, torna as baterias pouquíssimo práticas e, consequentemente, pouco interessantes do ponto de vista de outros públicos profissionais cujos trabalhos se beneficiam ou que até mesmo são rigorosamente dependentes de instrumentos de avaliação e testagem para atingir patamares aceitáveis de qualidade. São exemplos desses públicos docentes, coordenadores de cursos que precisam realizar rápida e eficientemente diagnósticos de nivelamento de estudantes neles ingressantes e, finalmente, pesquisadores em aquisição e processamento da linguagem em contextos bilíngues e multilíngues. É no âmbito da questão aqui colocada que nos faz julgar muito relevante a confluência, com vistas ao cotejamento, de estudos sobre tarefas, métodos e métricas diversificadas para a avaliação de L2 e, especialmente, para o caso do português como língua adicional, tal como proposto no dossiê que ora chega aos leitores da Revista da ABRALIN.

\section{A pluralidade do português como língua adicional}

Especificamente ao pensarmos a história linguística brasileira, talvez seja pertinente dar saliência à pergunta sobre o momento no qual o português deixou de ser uma segunda língua para tornar-se vernáculo. Segundo Mattos e Silva (2004), a narrativa da língua portuguesa no território nacional brasileiro pode ser contada como o trajeto de seu papel em um contexto de multilinguismo difuso para o papel de língua nacional, língua esta que cujo estabelecimento como aquela de uso dominante,

\footnotetext{
${ }^{3}$ https://www.gov.br/inep/pt-br/areas-de-atuacao/avaliacao-e-exames-educacionais /celpe-bras
} 


\section{REVISTA DA ABRALIN}

majoritário e nativo da vasta maioria dos brasileiros tem início na metade do século XVIII. Ou seja, o português foi uma língua de contato e, provavelmente, uma língua adicional daqueles que povoaram o Brasil durante pelo menos três séculos desde os primórdios documentados da colonização portuguesa nos territórios que hoje compõem o estado nacional brasileiro.

Não obstante a ponderação acima, a questão da avaliação de competências e habilidades linguísticas, tal como argumentado anteriormente, se impõe no contexto das ideias que formatam as ciências linguísticas modernas. Trata-se de uma questão que se formula em diálogo com a testagem educacional objetiva, a psicometria, a linguística aplicada e o entrelaçamento entre teoria linguística e aquisição de segunda língua tal como esses saberes se constituíram do século XX para nossos dias.

Neste recorte histórico, no Brasil, iniciativas formais de ensino do porttuguês como língua adicional, segundo Rocha (2019), remontam ao fim da década de 1950 e são marcadas por produção editorial de materiais didáticos para tal fim. A autora situa ainda a importância do surgimento de cursos de português no contexto de ensino de línguas diferentes do inglês em departamentos universitários nos EUA, e o papel da teorização sobre o ensino comunicativo de línguas para o estabelecimento da área então denominada "português língua estrangeira" (PLE), a partir dos anos de 1960 e 1970. Naquele período inicial de estabelecimento da área, o protagonismo dos professores Francisco Gomes de Matos, José Carlos Paes de Almeida Filho e Matilde Scaramucci, assim como o papel institucional de cursos ofertados na Universidade de São Paulo e na Universidade de Campinas, são igualmente rememorados pela autora.

As décadas de 1980 e 1990 testemunharam um grande crescimento do ensino de PLE, como demonstram Schlatter, Bulla e Costa (2020). Este segundo período é caracterizado pela adesão de várias universidades brasileiras ao movimento de ensino do vernáculo brasileiro para falantes de outras línguas. Segundo os autores, dentre tais universidades estiveram a Universidade de Brasília, a Universidade Federal da Bahia, Universidade Federal Fluminense, Universidade Federal de Minas Gerais, a Universidade Federal de Pernambuco, a Universidade Federal do Rio Grande do Sul e a Universidade Federal do Rio de Janeiro.

No século atual testemunhamos uma clara expansão e internacionalização da relevância do português como língua adicional como área de atuação profissional no ensino e também como objeto dos estudos da linguagem. Diniz (2020) oferece uma discussão crítica detalhada do papel de políticas linguísticas brasileiras nesse processo de expansão, demonstrando o impacto de diretrizes do Ministério das Relações Exteriores brasileiro, através do Departamento Cultural do Itamaraty. Tais diretrizes rezam que o referido departamento tem a função de divulgação da cultura brasileira no exterior, com ênfase na divulgação da "língua portuguesa falada no Brasil" (Diniz, 2020, p. 46). Nesse contexto, segundo o autor, surgem no exterior Centros Culturais Brasileiros (CCBs), Núcleos de Estudos Brasileiros (NEBs) e a posição de leitorado brasileiro em instituições de ensino no exterior. Retomando elementos da argumentação de Rocha (2019), assim como de Schlatter, Bulla e Costa (2020), cabe destacar o papel da bateria CELPE-Bras no processo de institucionalização contemporâneo do ensino e da aprendizagem do português, em particular das variantes brasileiras, como língua adicional. 


\section{REVISTA DA ABRALIN}

Ao mesmo tempo, mudanças conceituais relevantes passaram a ocupar a reflexão sobre as línguas diferentes de uma língua materna ou língua dominante. Uma dessas mudanças, cujos detalhes são discutidos em Leffa e Irala (2014) é aquela através da qual os adjetivos "estrangeira" e "segunda" passaram a ser sistematicamente substituídos por "adicional" nos discursos acadêmicos brasileiros sobre tais línguas. A denominação português como língua adicional se torna corrente nos discursos dos estudos linguísticos brasileiros, sendo atualmente a essa a denominação da área de atuação docente e pesquisa (Schlatter, Bulla e Costa, 2020). Leffa e Irala (2014) demonstram que essa mudança conceitual ocorre em resposta a inadequações da conotação cronológica de "segunda", pois nem sempre este é o caso, haja vista contextos multilíngues.

Tampouco é desprovido de inadequações patentes a conotação de "estrangeiro", ainda como demonstram Leffa e Irala (2014). O português, por exemplo, pode não ser a primeira língua adquirida de um falante de língua autóctone de povos originários do Brasil, de falantes de línguas de imigração ou de usuários da Língua Brasileira de Sinais. Mas seria, então, o português uma língua "estrangeira", uma vez que esses falantes podem ser tão legitimamente portadores de cidadania brasileira quanto os falantes do português como a primeira língua por eles adquirida?

Igualmente específica é a situação emergente de ensino do português como língua adicional que passa a ser denominada, mais recentemente, de português como língua de acolhimento. Essa denominação, como nos ensinam Miranda e Lopes (2019), recobre as práticas de ensino do português como resposta às iniciativas de acolhimento de imigrantes do exterior que passam a chegar no país no século atual em situação de deslocamento compulsório de seus territórios de origem, o que é o caso de refugiados. Tais práticas de ensino da língua oficial brasileira, segundo as autoras, passam a ocorrer em conjunto com outras iniciativas de acolhimento dessas populações, iniciativas essas comumente orquestradas por entidades da sociedade civil tais como organizações não-governamentais e religiosas, assumindo um caráter de resposta a uma crise humanitária, e com frequência dependendo de trabalho voluntário executado por indivíduos não necessariamente egressos de formações profissionais que fornecem a qualificação para o exercício de suas funções.

O contexto emergente do português como língua de acolhimento traz singularidades tanto do ponto de vista das necessidades linguísticas e comunicativas dos aprendizes quanto no tocante à preparação das pessoas que exercem a atividade docente, como salientado por Miranda e Lopes (2019). Ainda, e não menos, tais singularidades não podem permanecer invisibilizadas a discussões sobre a avaliação das habilidades linguísticas da população de aprendizes assim contemplados.

Nas últimas décadas, com as diásporas lusófonas ao redor do mundo, o ensino do português como língua de herança vem ganhando terreno tanto na Europa (e.g., Souza, 2016; Melo-Pfeifer, 2015) como nos Estados Unidos (e.g., Jouët-Pastré, 2011). Esse interesse pela manutenção da língua portuguesa por comunidades diaspóricas influenciou diretamente a oferta de cursos de português em universidades, escolas, centros comunitários e até igrejas em regiões habitadas por imigrantes portugueses, brasileiros, angolanos e cabo-verdianos. O crescimento no número de falantes e alunos de português como língua de herança tem gerado novas pesquisas acadêmicas nas áreas de ensino (e.g., Silva e Costa, 2018), aquisição (e.g., Flores, 2015) e até mesmo avaliação (e.g., Silva, no prelo). O 


\section{REVISTA DA ABRALIN}

trabalho com línguas de herança traz novos desafios para teorias e práticas de ensino e avaliação. Por definição, a população de falantes de herança é bastante heterogênea. Os diferentes graus de exposição à língua de herança e de instrução formal fazem com que qualquer proposta educacional se complexifique muito rapidamente pois os parâmetros de avaliação da performance linguística não obedecem qualquer tipo de estandardização vigente, nem para falantes nativos e muito menos para falantes de L2. Do ponto de vista do desenvolvimento linguístico, falantes de herança exibem características próprias, uma vez que seu léxico e sua gramática apresentam propriedades oriundas de um processo de aquisição bilíngue onde as línguas envolvidas ocupam diferentes espaços de fala. Soma-se a esta questão, o fato de que em termos sociolinguísticos as línguas de herança possam ter um status diferenciado, com uma maior aceitação de padrões lexicais e morfossintáticos incorporados da língua dominante.

Todo esse conjunto de fatores faz com que os falantes de herança tenham necessidades pedagógicas distintas aos falantes de L2. No âmbito da avaliação, muito tem se falado sobre problemas relacionados à validade de face dos testes usados, com um enfoque específico nas consequências sociais de tais elementos de testagem, uma vez que os testes tradicionais tendem a não dar o mesmo valor às áreas da linguagem nas quais falantes de herança têm maior facilidade, como as variações pragmáticas, conversacionais e culturais (Leeman, 2012). Vários estudos mostram que os testes de nivelamento comumente usados tendem a sobrevalorizar certas propriedades formais da língua alvo, o que cria problemas de confiabilidade nos resultados dos testes no caso dos falantes de herança (Fairclough, 2006). Cada vez mais, autores apontam a necessidade de se reestruturar as ferramentas de avaliação para falantes de herança (e.g., MacGregor-Mendonza, 2012). Como ainda são poucos os estudos específicos para o português nesta área, todos os demais trabalhos sobre avaliação de línguas adicionais em nosso idioma são extremamente importantes se quisermos avançar também na criação de mecanismos de testagem para essa população.

Essas questões por si só são reveladoras da pluralidade dos perfis de aprendizes e contextos de aprendizagem que devem ser levados em consideração ao pensarmos no português como uma língua de cuja competência e habilidade se soma a outra, ou seja, como uma língua adicional.

\section{O nosso dossiê}

Neste dossiê reunimos relatos de propostas metodológicas para a avaliação do português como língua adicional, língua de acolhimento e língua de herança que contemplam estudos sobre a operacionalização, através de métodos e técnicas de avaliação linguística, de uma gama de construtos compreendidos como componentes e habilidades da capacidade de uso eficiente da língua portuguesa como língua não primária. Os métodos e técnicas de operacionalização de tais construtos incluem testes, escalas, tarefas ou dispositivos de classificação ou de mensuração, seja baseada em normatização ou baseada em critérios, que envolvam métodos de testagem, escalas, dispositivos e tarefas 


\section{REVISTA DA ABRALIN}

que avaliem subcomponentes específicos de habilidades linguísticas (ex.: competência lexical, discriminação fonêmica, fluência de fala, destreza no reconhecimento visual de palavras etc.).

Entendemos, tal como afirmado acima, que os trabalhos cujos relatos compõem este dossiê guardam interesse tanto para os colegas que atuam direta ou indiretamente com a testagem do português em iniciativas oficiais e institucionalizadas, tal como o CELPE-Bras, como a um espectro mais amplo de leitores. Assim, acreditamos que os artigos presentes neste dossiê são de interesse para pesquisadores das áreas de aquisição de segunda língua e do processamento da linguagem por bilíngues e para pesquisadores e professores atuantes na área de ensino do português como língua adicional para além da conotações restritivas, e potencialmente marcadas por matizes ideológicos, do sintagma "língua estrangeira". Esperamos, portanto, que este dossiê vá ao encontro dos interesses de uma ampla comunidade de estudiosos e profissionais cujos trabalhos se centram no português como L2 ou que simplesmente o incluam, contemplando o português para surdos, o português como língua de acolhimento e os docentes e/ou linguistas que se dedicam à manutenção da língua portuguesa em comunidades de falantes do idioma como língua de herança.

Nosso dossiê se inicia com a temática de avaliação de habilidades orais. O primeiro texto do dossiê Proficiência oral em português brasileiro: cenário, contextos de avaliação e de instrução e questionamentos, de Anna Smirnova Henriques (PUC-SP), Thaiza Barros (PUC-SP) e Sandra Madureira (PUC-SP), apresenta uma revisão de literatura sobre o tema. As autoras, em seu texto, apontam as contribuições que uma perspectiva foneticamente embasada traz para o desenvolvimento da avaliação da proficiência oral do Português como Língua Estrangeira.

Em seguida, o artigo de Laura Ferreira (UNILA), Componentes da habilidade oral: uma análise das propriedades dos itens analíticos do exame Celpe-Bras, apresenta uma investigação, apoiada no modelo da habilidade comunicativa da linguagem de Bachman (1990), de como os subcomponentes de habilidade oral de uma das avaliações da bateria do CELPE-Bras interagem para construção da nota do avaliador-observador. A pesquisadora, no segundo artigo presente neste dossiê, demonstra, por meio de dados empíricos, que a tarefa de avaliação oral do exame interfere na forma como os subcomponentes da habilidade linguística interagem.

Ainda no escopo das avaliações de habilidades orais, o terceiro texto do dossiê Analyzing oral performance of Portuguese as a Host Language speakers through the Outcome Achievement measure, de Ana Flavia Boeing Marcelino (UFSC) e Raquel Carolina de Souza Ferraz D'Ely (UFSC), aborda tal avaliação na perspectiva de falantes de português como língua de acolhimento. O relato discute a avaliação do desempenho oral de estudantes adultos imigrantes com base em duas escalas da medida Outcome Achievement, demonstrando que a medida apresenta um alternativa a métodos de avaliação do desempenho oral que se baseiam em medidas mais tradicionais, por levar em consideração os objetivos imediatos de uso da língua da população imigrante.

Por meio de uma pesquisa qualitativa, de caráter descritivo, Leandro Rocha Vieira (IFRS), Júlia Sonaglio Pedrassani (IFRS) e Carina Fior Postingher Balzan (IFRS) contribuem em seu relato de pesquisa, Lingua e cidadania: a apropriação da língua portuguesa por imigrantes haitianos no IFRS-Campus Bento Gonçalves, com a discussão sobre o português como língua de acolhimento, por meio de 


\section{REVISTA DA ABRALIN}

uma avaliação da produção oral de imigrantes haitianos. O quarto artigo do dossiê reflete sobre a proficiência do alunado por meio de entrevistas semi-estruturadas analisadas a partir dos descritores do Quadro Europeu Comum de Referência.

A avaliação do português como segunda língua para população surda é o foco da pesquisa do quinto artigo deste dossiê, O cloze como indicador do desenvolvimento linguístico e da representação emergente do português brasileiro, de Lia Abrantes Antunes Soares (UFRJ). A autora, a partir de uma perspectiva sociocognitivista, da Linguística Cognitivo-Funcional, analisa a avaliação das habilidades de leitura de surdos por meio do teste cloze.

A bateria do CELPE-Bras, desta vez com uma análise de uma tarefa escrita, volta a ser objeto de análise no sexto artigo deste dossiê, O perfil argumentativo da Tarefa IV no exame Celpe-Bras, de Juliana Roquele Schoffen (UFRGS), Gabrielle Rodrigues Sirianni (UFRGS) e Simone Paula Kunrath (Escola Bem Brasil). Com o objetivo de contribuir para um maior conhecimento sobre o exame, as autoras identificaram, em uma análise das 43 tarefas IV aplicadas entre 1998 e 2019, dois perfis recorrentes de esferas, gêneros do discurso e propósitos comunicativos.

Lingua de herança, adolescência e avaliação, de Daniella F. D. Ringhofer (Universidade de Viena) e Ebal Sant'Anna Bolacio Filho (UFF), é o sétimo artigo do dossiê. A partir de um relato de experiência, os autores refletem sobre aspectos históricos relacionados ao conceito de Língua de Herança na situação do Português como Língua de Herança no sistema público escolar austríaco e as demandas avaliativas especificamente surgidas nos últimos anos em tal contexto. O texto apresenta um relato de um projeto piloto de testes de proficiência de POLH nos moldes de testes existentes para a língua alemã, que apresentou resultados satisfatórios e pode servir de base para futuros exames de proficiência de POLH nos países de língua alemã.

Evellyn Gasparello (UTFPR) e Jeniffer Imaregna Alcantara de Albuquerque (UTFPR) são autoras do último, o oitavo, artigo do dossiê, Guia avaliativo de português como língua adicional para crianças estrangeiras bilíngues, que propõe orientações para a avaliação de crianças estrangeiras que estejam em processo de aquisição do português brasileiro em imersão. A partir da solicitação de pais de crianças nesse contexto, as autoras criaram um guia para a língua portuguesa, baseado no guia elaborado por McLaughlin et al (1995).

No conjunto, acreditamos que nosso dossiê reflete nosso desejo de que a avaliação seja discutida como um objeto de saber especializado e de reflexão sistematizada, como dissemos na introdução desta apresentação, no processo de ensino-aprendizagem do português como língua adicional, em seus mais variados contextos. Nossa motivação para reunirmos esta coletânea de textos é que as experiências e as análises aqui trazidas permitam o desenvolvimento de reflexões sobre o tema e o desenvolvimento de novos instrumentos de avaliação de competências e habilidades linguísticas confiáveis, justos e acessíveis para todos os interessados na área. 


\section{REVISTA DA ABRALIN}

\section{Agradecimentos}

Agradecemos a todos os autores e pareceristas que fizeram todo o trabalho de forma ágil, cordial e colaborativa, mesmo com um prazo de dois meses entre o fechamento das submissões e o lançamento deste periódico. Trazemos aqui o nome de alguns pareceristas que, como não tiveram os artigos revisados incluídos neste dossiê, não serão lidos ao longo das páginas, mas precisam ser agradecidos: Giselli Mara Silva (UFMG), Leandro Rodrigues Alves Diniz (UFMG), Maria Teresa Valdez (University of Rochester), Arabie Hermont (PUC-MG), Josiane Marques (UFLA), Denise Weiss (UFJF). Agradecemos também o aluno Manoel Siqueira, bolsista da Revista da Abralin, responsável por colocar os artigos no modelo final, sempre com muita agilidade e com gentileza. Agradecemos a Raquel Freitag (UFS), editora da Revista da Abralin, pela oportunidade de lançamento deste dossiê.

\section{REFERÊNCIAS}

CONSOLO, D. A.; TEIXEIRA DA SILVA, V. L. Em defesa de uma formação linguística de qualidade para professores de línguas estrangeiras: o exame EPPLE. Horizontes da Linguística Aplicada, vol. 13, no. 1, 2014, pp. 63-87.

DINIZ, L. R. A. Para Além das Fronteiras: A Política Linguística Brasileira de Promoção Internacional do Português. Belo Horizonte: Editora da UFMG, 2020.

FAIRCLOUGH, M. Language placement exams for heritage speakers of Spanish: Learning from students' mistakes. Forreign Language Annals, v. 39, n. 4, 2006, pp. 594-604.

FLORES, C. M. M. Understanding heritage language acquisition. Some contributions from the research heritage speakers of European Portuguese. Lingua, v. 164, 2015, pp. 251-265.

JOUËT-PASTRÉ, C. Mapping the world of the heritage language learners of Portuguese: Results from a national survey at college level. Portuguese Language Journal, v. 5, 2011, pp. 325-348.

LEEMAN, J. Investigating language ideologies in Spanish as a heritage language. In Beaudrie, S.; Fairclough, M. (eds). Spanish as a Heritage Language in the United States: The state of the field. Washington, DC: Georgetown University Press, 2012, pp. 43-60.

LEFFa, V. J..; IRALA, V. B. O ensino de outra(s) língua(s) na contemporaneidade: questões conceituais e metodológicas. In: Leffa, V. J..; Irala, V. B. (orgs). Uma Espiadinha na Sala de Aula: Ensinando Línguas Adicionais no Brasil. Pelotas: Educat - Editora da Universidade Católica de Pelotas, 2014.

MATTOS E SILVA, R. V. Ensaios para uma Sócio-História do Português Brasileiro. São Paulo: Parábola, 2004.

MACGREGOR-MENDONZA, P. Spanish as a heritage language assessment: Successes, failures, lessons learned. Heritage Language Journal, v. 9, n.1, 2012, pp 1-26.

MCNAMARA, T. Measuring Second Language Performance. London.New York: Addison-Welsely Longman, 1996. 


\section{REVISTA DA ABRALIN}

MCNAMARA, T. Language Testing. Oxford: Oxford University Press, 2000.

MCNAMARA, T. Language testing. In : Davies, A. ; Elder, C. (orgs). The Handbook of Applied Linguistics. Malden: Blackwell Publishing, 2004.

MELO-PFEIFER, S. The role of the family in heritage language use and learning: impact on heritage language policies. International Journal of Bilingual Education and Bilingualism, v. 18, n. 1, 2015, pp. 26-44.

MIRANDA, Y. C. C.; LOPEZ, A. P. A. Considerações sobre a formação de professores no contexto do Português como Língua de Acolhimento. In: Ferreira, L. C.; Perna, C.; Gualda, R.; Leurquin, E. V. L. F. (orgs.). Língua de Acolhimento: Experiências no Brasil e no Mundo. Belo Horizonte: Mosaica, 2019.

PERRENOUD, P. Avaliação : Da Excelência à Regulação das Aprendizagens - Duas Lógicas. Porto Alegre : Artmed, 1999.

ROCHA, N. A. O ensino de português língua estrangeira no Brasil: ontem e hoje. Revista de Letras, Artes de Comunicação, Vol. 13, no. 1, 2019, p. 101-114.

SCARAMUCCI, M. O exame Celpe-Bras e a proficiência do professor de português para falantes de outras línguas. Revista DIGILENGUA, no. 12, 2012, p. 48-67.

SCHLATTER, M.; BULLA, G. S.; COSTA, E. V. Português como Língua Adicional: uma entrevista com Margarete Schlatter. Revista Virtual de Estudos da Linguagem, Vol. 18, no. 35, 2020. p. 489-508.

SILVA, G. Assessment in community-based heritage language schools: The case of Portuguese. In: Rodriguez Gonzales, E.; Rivera, R. (eds). Integrating Context-Based Approaches to Language Assessment in Multilingual Settings. PLACE: Language Science Press. (no prelo).

SILVA, G.; COSTA, E. V. What do teachers want? Professional development opportunities for instructors of Portuguese as a heritage language. Journal of the National Council of Less Commonly Taught Languages, v. 23, 2018, pp.41-62.

SOUZA, A. Is Brazilian Portuguese being taught as a community of heritage language? Language Issues: The ESOL Journal, v. 27, n. 1, 2016, pp 21-28.

SPOLSKY, B. Measured Words - The Development of Objective Language Testing. Oxford/New York: Oxford University Press, 1995. 